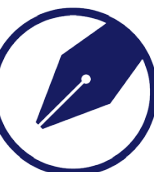

\title{
Supporting Conversion Section of Hydrogen Production Unit by Membrane Modules to Produce Extra-Pure Hydrogen and Improving Equilibrium Conversion
}

\author{
M. Sarkarzadeh, M. Farsi* \\ Department of Chemical Engineering, Chemical and Petroleum Engineering School, Shiraz University, Shiraz, Iran \\ Email: farsi@shirazu.ac.ir
}

\begin{abstract}
The main object of this research is the modification of an industrial hydrogen production unit with palladiumbased membrane modules to produce extra-pure hydrogen and shift reactions toward the hydrogen production side. The considered hydrogen production unit includes steam reformer, high and low temperature shift converters, carbon dioxide absorption tower, and methanator. The membrane modules are applied in the catalytic reactors and hydrogen is simultaneously penetrated from the reaction zone toward the sweep gas. In the first step, both conventional and membranesupported processes are heterogeneously models based on the mass and energy balance equations at steady state condition. Then, the simulation results of conventional process are compared with the plant data to prove the validity of the developed model. Finally, the simulation results of conventional and membrane-supported processes are compared under the same operating condition. In general, applying the membrane module on the system increases hydrogen production rate from 63.95 to 67.21 mole s$^{-1}$. Based on the simulation results, supporting the conventional with the membrane module increases hydrogen production rate by $5.1 \%$.
\end{abstract}

Keywords: hydrogen, steam methane reforming, heterogeneous modeling, palladium-based membrane

\section{Nomenclature}

\begin{tabular}{|c|c|}
\hline$a_{v}$ & Specific surface area $\left(\mathrm{m}^{2} \mathrm{~m}^{-3}\right)$ \\
\hline$A_{C}$ & Cross-sectional area $\left(\mathrm{m}^{2}\right)$ \\
\hline$C$ & Concentration $\left(\right.$ mole $\left.\mathrm{m}^{-3}\right)$ \\
\hline$D_{b}$ & Bed diameter $(\mathrm{m})$ \\
\hline$d$ & Particle diameter $(\mathrm{m})$ \\
\hline$D_{e f}$ & Effective diffusion coefficient $\left(\mathrm{m} \mathrm{s}^{-2}\right)$ \\
\hline$D_{i j}$ & Binary diffusion coefficient $\left(\mathrm{m} \mathrm{s}^{-2}\right)$ \\
\hline$E_{j}$ & Activation energy of reaction $\mathrm{j}\left(\mathrm{kJ} \mathrm{mol}^{-1}\right)$ \\
\hline$F_{p}$ & Shape factor \\
\hline$h_{f}$ & Heat transfer across particle $\left(\mathrm{W} \mathrm{m}^{-2} \mathrm{~K}^{-1}\right)$ \\
\hline$h_{1}$ & Liquid hold up on each tray $\left(\mathrm{m}^{3}\right)$ \\
\hline$h_{f}$ & Heat transfer in furnace $\left(\mathrm{W} \mathrm{m}^{-2} \mathrm{~K}^{-1}\right)$ \\
\hline$H_{n}$ & Enthalpy of stream exit $\mathrm{n}^{\text {th }}$ tray $\left(\mathrm{J} \mathrm{mol}^{-1}\right)$ \\
\hline$\Delta H_{j}$ & Heat of reaction $\mathrm{j}(\mathrm{J})$ \\
\hline$K_{e q}$ & Equilibrium constant \\
\hline$K_{i}$ & Adsorption constant of species i \\
\hline$k_{j}$ & Rate constant of reaction $\mathrm{j}\left(\mathrm{kmol} \mathrm{kg}_{\mathrm{cat}}^{-1} \mathrm{~h}^{-1}\right)$ \\
\hline$k_{g i}$ & Mass transfer diffusion in porous media $\left(\mathrm{m} \mathrm{s}^{-1}\right)$ \\
\hline$K_{\text {value }}$ & Phase equilibrium constant \\
\hline$L_{n}$ & Liquid flow rate $\left(\right.$ mole s$\left.^{-1}\right)$ \\
\hline$M_{w}$ & Molecular weight $\left(\mathrm{kg} \mathrm{kmol}^{-1}\right)$ \\
\hline$P$ & Pressure (bar) \\
\hline
\end{tabular}




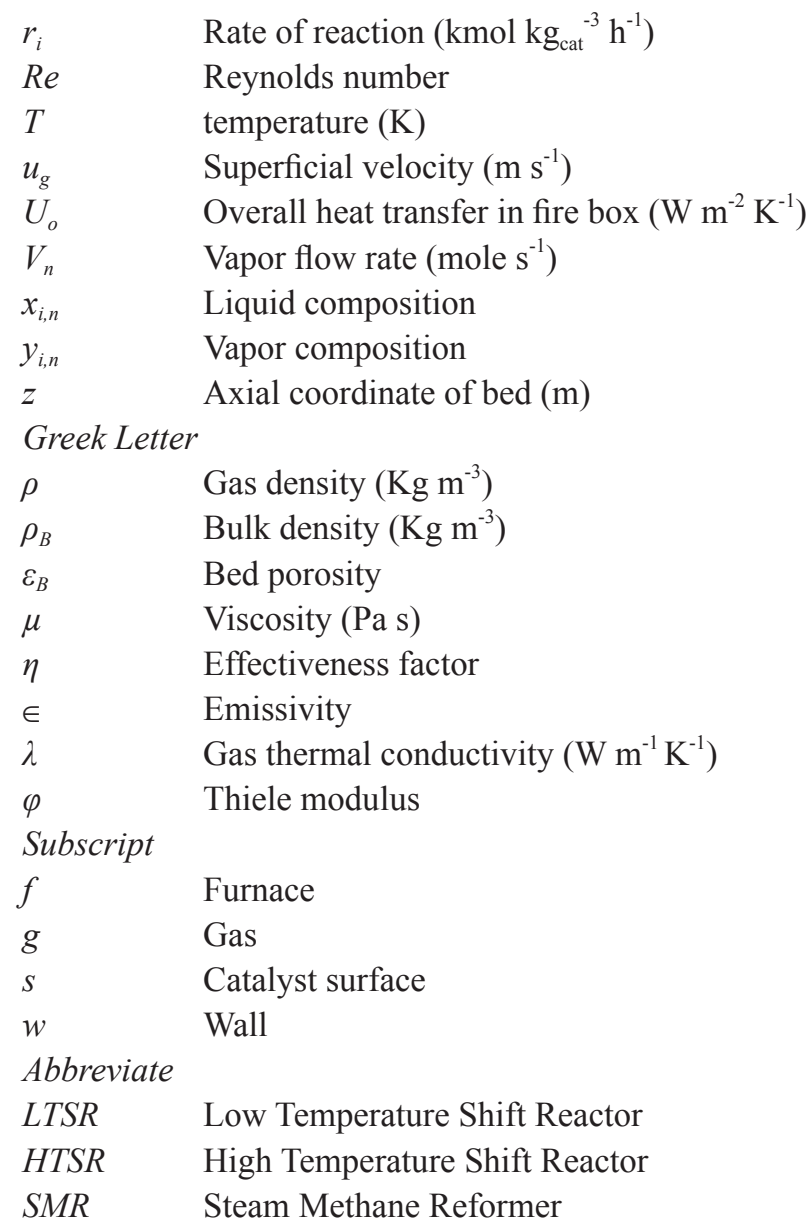

\section{Introduction}

Typically, hydrogen as the most abundant element on the earth plays a key role in the development of human societies. Ammonia, dimethyl ether, methanol, gasoline, and various aldehydes are catalytically produced from a mixture of hydrogen and carbon monoxide. In the oil refinery units, hydrogen is used as the hydrogenation agent in the hydrocracking, reforming, and hydrotreating units. Besides, hydrogen is directly applied in the power plants ${ }^{[1]}$, fuel cells ${ }^{[2]}$, aerospace ${ }^{[3]}$, semiconductors $^{[4]}$, and automotive industries ${ }^{[5]}$. Due to the high global demand for hydrogen, different routes, feedstocks, and technologies have been developed to produce hydrogen ${ }^{[6]}$. Reforming and partial oxidation of hydrocarbons, coal gasification, electrolysis of alkaline solutions, and fermentation of organic substrates are common technologies developed to produce hydrogen. In the reforming process, the hydrocarbons react with a reforming agent in the presence of a heterogeneous catalyst, and hydrogen, carbon monoxide, and carbon dioxide are produced. Since pure hydrogen is applied in the fossil fuel upgrading units in an oil refinery, the steam reforming of methane is more attractive compared to other reforming types due to high hydrogen yield ${ }^{[7]}$. In the old technologies, the produced carbon monoxide through reforming is converted to hydrogen in the high and low temperature shift reactors, and then the produced carbon dioxide is separated from products in an absorption column ${ }^{[8]}$. In the new technologies, a part of carbon monoxide is converted to hydrogen in the high temperature shift converter, and the outlet stream is purified in a PSA unit to produce pure hydrogen ${ }^{[9]}$. Dincer and Acer presented a good review on the hydrogen production routes and investigated the environmental impact, operating and investment costs, and efficiency of each method ${ }^{[10]}$.

Between developed technologies to integrate reaction and separation units including sorption enhanced and membrane separation, the membrane modules are more efficient due to low operating cost, complexity, and high flexibility ${ }^{[11]}$. Many researchers have focused on the effects of supporting reforming and shift reactors by membrane modules on the operating conditions, hydrogen production, purity, and methane conversion. Roses et al. supported a steam methane reformer with a hydrogen permselective membrane module and investigated the effect of operating conditions on the process performance ${ }^{[12]}$. Although increasing operating pressure decreases the conversion based on Le Chatelier's principle, it enhances the equilibrium conversion by decreasing the hydrogen concentration in the system. Silva et al. formulated a 
multi-objective optimization problem to calculate the optimal operating conditions of a membrane supported reformer considering methane conversion and hydrogen recovery as the objective functions ${ }^{[13]}$. Applying the optimal condition on the reformer increased the methane conversion and hydrogen recovery to $99.9 \%$ and $98.2 \%$, respectively. Farsi and Shahosseini modified a membrane supported steam reformer by considering some quench points on the reactor body ${ }^{[14]}$. The results showed that the proposed strategy could decrease pressure drop and increase the hydrogen production rate. Shigarov et al. reviewed the experimental and theoretical efforts on the application of Pd based membranes in catalytic reactors to produce hydrogen through steam methane reforming ${ }^{[15]}$.

In the hydrogen unit, produced carbon monoxide is catalytically converted to hydrogen and carbon dioxide in the shift converter. Mendes et al. presented a comprehensive review on the shift reaction and investigated the effects of supporting shift reactors with the membrane module on the process performance ${ }^{[16]}$. Boutikos and Nikolakis proved the superior performance of carbon dioxide removal compared to the hydrogen separation in the shift reactor when the feed stream is carbon dioxide-rich ${ }^{[17]}$. In the old technologies, the outlet product from the separation section feeds to the methanator to control hydrogen purity. Ohya et al investigated the effect of steam removal in the methanator by membrane module on the equilibrium conversion of reactions. The results showed that the steam removal by using the membrane module enhanced the equilibrium conversion when the inlet stream to the methanator was $\mathrm{CO}$ and $\mathrm{CO}_{2}$ diluted ${ }^{[18]}$.

The main object of the present research is supporting the reformer, low and high temperature shift reactors, and methanator in an industrial hydrogen production unit with the palladium-based membrane modules to produce ultrapure hydrogen and increasing production capacity by shifting the equilibrium limitations. In general, the palladium-based membranes are used in hydrogen extraction because of their high permeability, selectivity, and good surface properties ${ }^{[19]}$. In this regard, the proposed membrane supported and conventional processes are modeled based on the mass and energy balance equation at steady state condition. Then, the performance of the membrane supported configuration is compared with the conventional process.

\section{Process description}

\subsection{Conventional design}

Figure 1 illustrates the process flow diagram of the hydrogen production unit in a domestic oil refinery ${ }^{[8]}$. In the first step, the chlorine and sulfur contaminants in the feed stream are removed in the desulphurization and dechlorination guard reactors. Then, the preheated feed stream mixed with superheated steam at the desired ratio of 7.06. The prepared mixture feeds to the coil placed in the radiation part of furnace. During steam reforming, methane is converted to carbon dioxide, carbon monoxide, and hydrogen over the $\mathrm{Ni}-\mathrm{Al}_{2} \mathrm{O}_{3}$ catalyst. In the second step, the temperature of outlet product from the reformer is regulated in a cooler and feeds to the shift converters. In the shift reactors, the carbon monoxide and steam are catalytically converted to hydrogen and carbon dioxide. Afterward, the outlet stream from shift converters feeds to an amine absorption column to regulate carbon dioxide concentration in the product. Finally, the concentrations of carbon dioxide and carbon monoxide in the product stream decrease to an acceptable level in the methanator. Table 1 shows the reactor design data, catalyst specification, and operating conditions in the hydrogen unit.

Table 1. The reactor, catalyst design data and feed operating conditions in the hydrogen production unit

\begin{tabular}{|c|c|c|c|c|c|c|}
\hline & & \multicolumn{2}{|c|}{ Reactor } & \multirow{2}{*}{$\frac{\text { Catalyst }}{\text { Diameter }(\mathrm{mm})}$} & \multicolumn{2}{|c|}{ Feed } \\
\hline & Reactions (Number) & Diameter (m) & Length (m) & & Temperature $(\mathrm{K})$ & Pressure (bar) \\
\hline Reformer & Reforming (1-3) & 0.12 & 11.43 & 16 & 809 & 19 \\
\hline HTSR & Shift conversion (9) & 2.45 & 3.2 & 8.47 & 623 & 15 \\
\hline LTSR & Shift reactions (9) & 2.45 & 3.440 & 4.36 & 487 & 12 \\
\hline Methanator & Methanation (1-3) & 1.7 & 2.895 & 5.4 & 523 & 15 \\
\hline
\end{tabular}




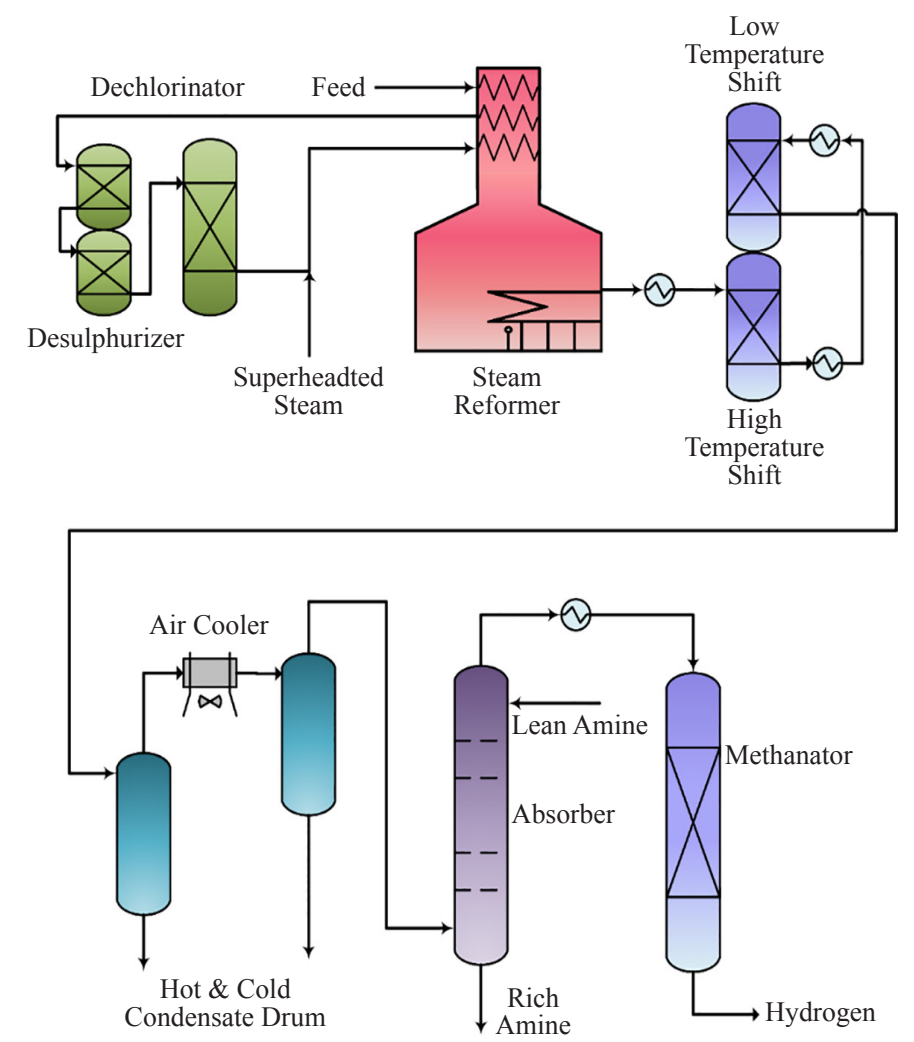

Figure 1. The schematic diagram of considered hydrogen production unit in Shiraz Oil Refinery

\subsection{Modified design}

Typically, the performance of industrial reformers and shift converters could be improved through the separation of hydrogen from the reaction zone ${ }^{[20-21]}$. To support the conventional reformer with the membrane modules, a hydrogen permselective tube is placed in the coil tube and the annulus space between tubes is packed with the catalyst. The sweep gas flows in the inner tube and hydrogen penetrates from the reaction zone to the sweep gas gradually. Also, the low and high temperature shift reactors are equipped with membrane tubes. The considered low and high temperature shift reactors are two shell and tube exchangers that the catalyst is packed in the shell side of reactors, while the sweep gas flows in the hydrogen permselective tubes. Although steam removal from the reaction zone has a significant effect on the equilibrium conversion in the methanator ${ }^{[18]}$, the main idea to support the methanator by hydrogen permselective membrane module is producing the extra-pure hydrogen.

\section{Reactions and kinetics}

\subsection{Reforming reactions}

Typically, the nickel oxide supported alumina catalyst is used in the industrial reformer to convert methane to syngas. Kinetics of reforming and water gas shift reactions are as:

$$
\begin{aligned}
& \mathrm{CH}_{4(g)}+\mathrm{H}_{2} \mathrm{O}_{(g)} \leftrightarrow \mathrm{CO}_{(g)}+3 \mathrm{H}_{2(g)} \\
& \mathrm{CH}_{4(g)}+2 \mathrm{H}_{2} \mathrm{O}_{(g)} \leftrightarrow \mathrm{CO}_{2(g)}+4 \mathrm{H}_{2(g)} \\
& \mathrm{CO}_{(g)}+\mathrm{H}_{2} \mathrm{O}_{(g)} \leftrightarrow \mathrm{CO}_{2(g)}+\mathrm{H}_{2(g)}
\end{aligned}
$$

The rate of reforming reactions on the commercial catalyst are as [14]: 


$$
\begin{aligned}
& \left.r_{1}=\frac{k_{1}}{P_{H_{2}}^{2.5}}\right)\left(P_{\mathrm{CH}_{4}} P_{\mathrm{H}_{2} \mathrm{O}}-\frac{P_{\mathrm{H}_{2}}^{3} P_{\mathrm{CO}}}{K_{1}}\right)
\end{aligned}
$$

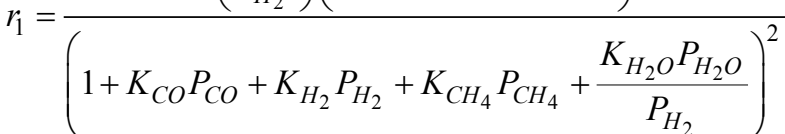

$$
\begin{aligned}
& \left(\frac{k_{2}}{P_{H_{2}}^{3.5}}\right)\left(P_{\mathrm{CH}_{4}} P_{\mathrm{H}_{2}} \mathrm{O}^{2}-\frac{P_{\mathrm{H}_{2}}^{4} P_{\mathrm{CO}_{2}}}{K_{2}}\right) \\
& r_{2}=\frac{\left(1+K_{\mathrm{CO}} P_{\mathrm{CO}}+K_{\mathrm{H}_{2}} P_{\mathrm{H}_{2}}+K_{\mathrm{CH}_{4}} P_{\mathrm{CH}_{4}}+\frac{K_{\mathrm{H}_{2} \mathrm{O}} P_{\mathrm{H}_{2} \mathrm{O}}}{P_{\mathrm{H}_{2}}}\right)^{2}}{\left(P^{3}\right.} \\
& r_{3}=\frac{\left(\frac{k_{3}}{P_{\mathrm{H}_{2}}}\right)\left(P_{\mathrm{CO}} P_{\mathrm{H}_{2} \mathrm{O}}-\frac{P_{\mathrm{H}_{2}} P_{\mathrm{CO}_{2}}}{K_{3}}\right)}{\left(1+K_{\mathrm{CO}} P_{\mathrm{CO}}+K_{\mathrm{H}_{2}} P_{\mathrm{H}_{2}}+K_{\mathrm{CH}_{4}} P_{\mathrm{CH}_{4}}+\frac{K_{\mathrm{H}_{2} \mathrm{O}} P_{\mathrm{H}_{2} \mathrm{O}}}{P_{\mathrm{H}_{2}}}\right)^{2}}
\end{aligned}
$$

\subsection{Shift reaction}

Industrially, the iron-chrome oxide and copper-zinc oxide catalysts are used in the high and low temperature shift converters, respectively. In the shift converter, carbon monoxide and steam react over the catalyst, and hydrogen is produced. The kinetic of shift reaction is as:

$$
\mathrm{CO}_{(g)}+\mathrm{H}_{2} \mathrm{O}_{(g)} \leftrightarrow \mathrm{CO}_{2(g)}+\mathrm{H}_{2(g)}
$$

The rates of shift reactions at high and low temperatures are as [22-23]:

$$
\begin{gathered}
r_{\mathrm{High}}=k\left(P_{\mathrm{CO}} P_{\mathrm{H}_{2} \mathrm{O}}-\frac{P_{\mathrm{CO}_{2}} P_{\mathrm{H}_{2}}}{K_{\text {eq }}}\right) \\
r_{\text {Low }}=k \frac{\left(P_{\mathrm{H}_{2} \mathrm{O}}-\frac{P_{\mathrm{CO}_{2} P_{\mathrm{H}_{2}}}}{K_{e q} \times P_{\mathrm{CO}}}\right)}{\left(1+\frac{K_{\mathrm{CO}_{2}} P_{\mathrm{CO}_{2}}}{P_{\mathrm{CO}}}\right)}
\end{gathered}
$$

\section{3 $\mathrm{CO}_{2}$ absorption}

As expressed in the literature, $\mathrm{CO}_{2}$ absorption in the aqueous solution of monoethanolamine (MEA) started with the formation of carbamate according to the zwitterion mechanism, followed by the hydration of $\mathrm{CO}_{2}$ to form $\mathrm{HCO}_{3}^{-} / \mathrm{CO}_{3}^{2-}$, and accompanied by the hydrolysis of carbamate ${ }^{[24]}$. The elementary rate of reaction is as [25]:

$$
r_{\mathrm{CO}_{2}}=k \mathrm{C}_{\mathrm{CO}_{2}} \mathrm{C}_{\mathrm{MEA}}
$$

\subsection{Methanation reaction}

In the methanator, the reforming reactions occur in the reverse direction on the nickel oxide supported alumina catalyst. Thus, the kinetic and intrinsic rate of reactions in the methanator and reformer are similar ${ }^{[26]}$.

\section{Process modeling}

In this section, both conventional and membrane supported reactors are modeled based on the mass and energy 
balance equations at steady state condition. The applied assumptions in the considered model are:

- The ideal gas law is acceptable because the compressibility factor is in range 0.99-1.0.

- The flow regime is plug due to the high Reynolds number.

- Mass and energy diffusions are negligible compared to convections ${ }^{[27]}$.

- The temperature gradient in the catalyst is negligible due to the small Biot Number ${ }^{[28]}$.

- The Palladium based membrane module is completely selective to hydrogen

\subsection{Reforming reactor}

In this part, the considered model to simulate the membrane-supported reformer is presented at steady state condition. Based on the considered assumptions, the mole balance equation in the gas and solid phases are as:

$$
\begin{aligned}
& -u_{g} \frac{d C_{i}^{g}}{d z}-a_{v} k_{g i}\left(C_{i}^{g}-C_{i}^{s}\right)-\frac{P_{m}}{A_{c}} J_{i}=0 \\
& a_{v} k_{g i}\left(C_{i}^{g}-C_{i}^{s}\right)+\rho_{B} \sum_{j=1}^{N} \eta_{j} r_{i j}=0
\end{aligned}
$$

The Ergun equation is applied to calculate the pressure drop along the coil tube ${ }^{[29]}$ :

$$
\frac{d p}{d z}=\frac{150 \mu_{g}\left(1-\varepsilon_{b}\right)}{d_{p}^{2} \varepsilon_{b}^{3}} u_{g}+\frac{1.75\left(1-\varepsilon_{b}\right) \rho_{g}}{d_{p} \varepsilon_{b}^{3}} u_{g}^{2}
$$

The energy balance equations in the gas and solid phases of the coil are as:

$$
\begin{aligned}
& -u_{g} C_{P} C_{t} \frac{d T_{g}}{d z}-a_{v} h_{f}\left(T_{g}-T_{s}\right)+\frac{U_{f} P}{A_{c}}\left(T_{f}-T_{g}\right)-\frac{U_{m} P_{m}}{A_{c}}\left(T_{g}-T_{m}\right)=0 \\
& a_{v} h_{f}\left(T_{g}-T_{s}\right)+\rho_{B} \sum_{j=1}^{N} \eta_{j} r_{i j}\left(-\Delta H_{j}\right)=0
\end{aligned}
$$

\subsection{Shift converters and methanator}

In this part, the developed model to simulate the shift and methanation reactors are presented at steady state condition. The mole balance equations in the gas and solid phases are as follows:

$$
\begin{aligned}
& -u_{g} \frac{d C_{i}^{g}}{d z}-a_{v} k_{g i}\left(C_{i}^{g}-C_{i}^{s}\right)-\frac{P_{m}}{A_{c}} J_{i}=0 \\
& a_{v} k_{g i}\left(C_{i}^{g}-C_{i}^{s}\right)+\rho_{B} \sum_{j=1}^{N} \eta_{j} r_{i j}=0
\end{aligned}
$$

The energy balance equations in both gas and solid phases are as follows:

$$
\begin{aligned}
& -u_{g} C_{p} C_{t} \frac{d T_{g}}{d z}-a_{v} h_{f}\left(T_{g}-T_{s}\right)-\frac{U_{m} P_{m}}{A_{c}}\left(T_{g}-T_{\text {Perm }}\right)=0 \\
& a_{v} h_{f}\left(T_{g}-T_{s}\right)+\rho_{B} \sum_{j=1}^{N} \eta_{j} r_{i j}\left(-\Delta H_{j}\right)=0
\end{aligned}
$$

\subsection{Membrane module}

The applied hydrogen permselective membrane modules in the processes could be classified into three main groups including ceramic, polymer, and metal membranes ${ }^{[30]}$. Although the ceramic membranes present acceptable stability and strength, the low selectivity is the main disadvantage of those modules. Besides, the polymeric membranes are highly 
selective and applied at low-temperature conditions due to low thermal and mechanical stability. Between synthesized membranes, the metal modules are wildly recommended to separate hydrogen from a gas mixture due to high thermal, mechanical and chemical stability and selectivity. In this research, due to high temperature and severe conditions, the Pd-Ag membrane module is selected to remove hydrogen from the reaction zone in the reformer, shift converter, and methanator. The mass and energy balance equations on the membrane modules are as:

$$
\begin{aligned}
& -u_{m} \frac{d C_{i}^{m}}{d z}+\frac{J_{i}}{A_{m}} P_{m}=0 \\
& -u_{m} C_{p} C_{t} \frac{d T_{m}}{d z}+\frac{U_{m} P_{m}}{A_{m}}\left(T_{g}-T_{P e r m}\right)=0
\end{aligned}
$$

The rate of hydrogen permeation through the Pd-Ag membrane module is calculated by [31]:

$$
J_{h}=6.33 \times 10^{-8} \frac{2 \pi e^{-\frac{E_{p}}{R T}}}{\ln \left(R_{o} / R_{i}\right)}\left(\sqrt{p_{h}^{R}}-\sqrt{p_{h}^{S}}\right)
$$

\section{4 $\mathrm{CO}_{2}$ absorption column}

Generally, the equilibrium and rate-based models are used to simulate the absorption columns ${ }^{[32]}$. In the equilibrium models, it is assumed that the rate of mass transfer between gas and liquid streams are high and the outlet streams are at the thermodynamic equilibrium. In the rate-based models, the rate of mass transfer between phases is low and calculated with the mass transfer correlations. In this work, the $\mathrm{CO}_{2}$ absorber column is simulated based on the mass and energy balance equations considering the equilibrium approach. It is confirmed that due to the non-ideality of the liquid phase, the activity coefficient of components in the liquid is calculated with the Wilson model ${ }^{[33]}$. The developed equation to simulate the absorption column are:

$$
\begin{aligned}
& L_{n-1} x_{i, n-1}+V_{n+1} y_{i, n+1}-V_{n} y_{i, n}-L_{n} x_{i, n}+r_{i j} h_{l}=0 \\
& L_{n-1} H_{n-1}+V_{n+1} H_{n+1}-L_{n} H_{n}-V_{n} H_{n}+\Delta H_{j}=0 \\
& y_{i, n}=K_{\text {value }} x_{i, n} \\
& \sum_{i=1}^{C} y_{i, n}=1 \\
& \sum_{i=1}^{C} x_{i, n}=1
\end{aligned}
$$

\section{Solution method}

Generally, the produced heat in the furnace is indirectly transferred to the gas stream in the coil tubes. To simplicity, it is assumed that the conductive heat resistance in the coil material is negligible. In the $\mathrm{CO}_{2}$ absorber, the mass and energy balance equations, solubility, and considered auxiliary equations develop a set of nonlinear algebraic equations. Also, the applied mass and energy balance equations on the reformer, shift converter, and methanator result in a set of ordinary differential equations. In this research, the proposed procedure by Sarkarzadeh et al. is applied to solve the developed equations $^{[8]}$.

\section{Results and discussion}

\subsection{Process performance}

In this section, the simulation results of conventional process are compared with the plant data to prove the validity of the developed model. Table 2 presents the relative absolute error of simulation results. It appears that the obtained model is 
capable to predict the performance of considered industrial hydrogen units.

Table 2. Comparison between simulation results and plant data

\begin{tabular}{ccccc}
\hline & & Simulation & Plant Data & Absolute Relative Error \\
\hline \multirow{2}{*}{ Reformer } & $\mathrm{H}_{2}$ Mole Fraction & 74.95 & 74.7 & $0.33 \%$ \\
& $\mathrm{CH}_{4}$ Mole Fraction & 10.42 & 10.33 & $0.86 \%$ \\
& HTSR Temperature [K] & 647 & 654 & $1.10 \%$ \\
& LTSR Temperature [K] & 491.3 & 491 & $0.06 \%$ \\
& Methanator Temperature & 545.1 & 550 & $0.89 \%$ \\
\hline
\end{tabular}

Based on the simulation results supporting the hydrogen production unit by the membrane module increases hydrogen production capacity by about $5.1 \%$ compared to the conventional process at the same feed condition. Typically, the hydrogen production rate in the conventional and membrane-supported units are 63.95 and $67.21 \mathrm{~mole} \mathrm{~s}^{-1}$, respectively. Generally, the outlet hydrogen from the methanation reactor and separated hydrogen by membrane modules are 65.01 and 26.19 mole s$^{-1}$, respectively. Also, supporting the catalytic reactors by membrane modules increases methane conversion about $5.15 \%$ compared to the conventional process.

\subsection{Steam methane reformer}

In this part, the effect of supporting reformer by membrane module on the rate of hydrogen production is presented at steady state condition. Figure 2(a) and (b) show the molar flow rate of hydrogen and methane along the membrane supported and conventional reformers. According to Le Chatelier's principle, the equilibrium conversion of reforming reactions increases by decreasing hydrogen concentration in the reaction zone. Permeation of produced hydrogen in the reformer toward the sweep gas decreases hydrogen concentration in the reaction zone and shifts the reforming reactions toward the right side. Based on the simulation results, the produced hydrogen in the membrane supported and conventional reformers are 62.50 and $59.33 \mathrm{~mole} \mathrm{~s}^{-1}$, respectively. Also, the methane conversion in the membrane supported and conventional reformers are $61.33 \%$ and $58.51 \%$, respectively. Typically, supporting the steam methane reformer by membrane modules increases hydrogen production and methane conversion by about $5.34 \%$ and $4.82 \%$ at the same operating condition, respectively. Also, the molar flow rate of hydrogen at the outlet sweep gas from the membrane module is $6.53 \mathrm{~mole} \mathrm{~s}^{-1}$.
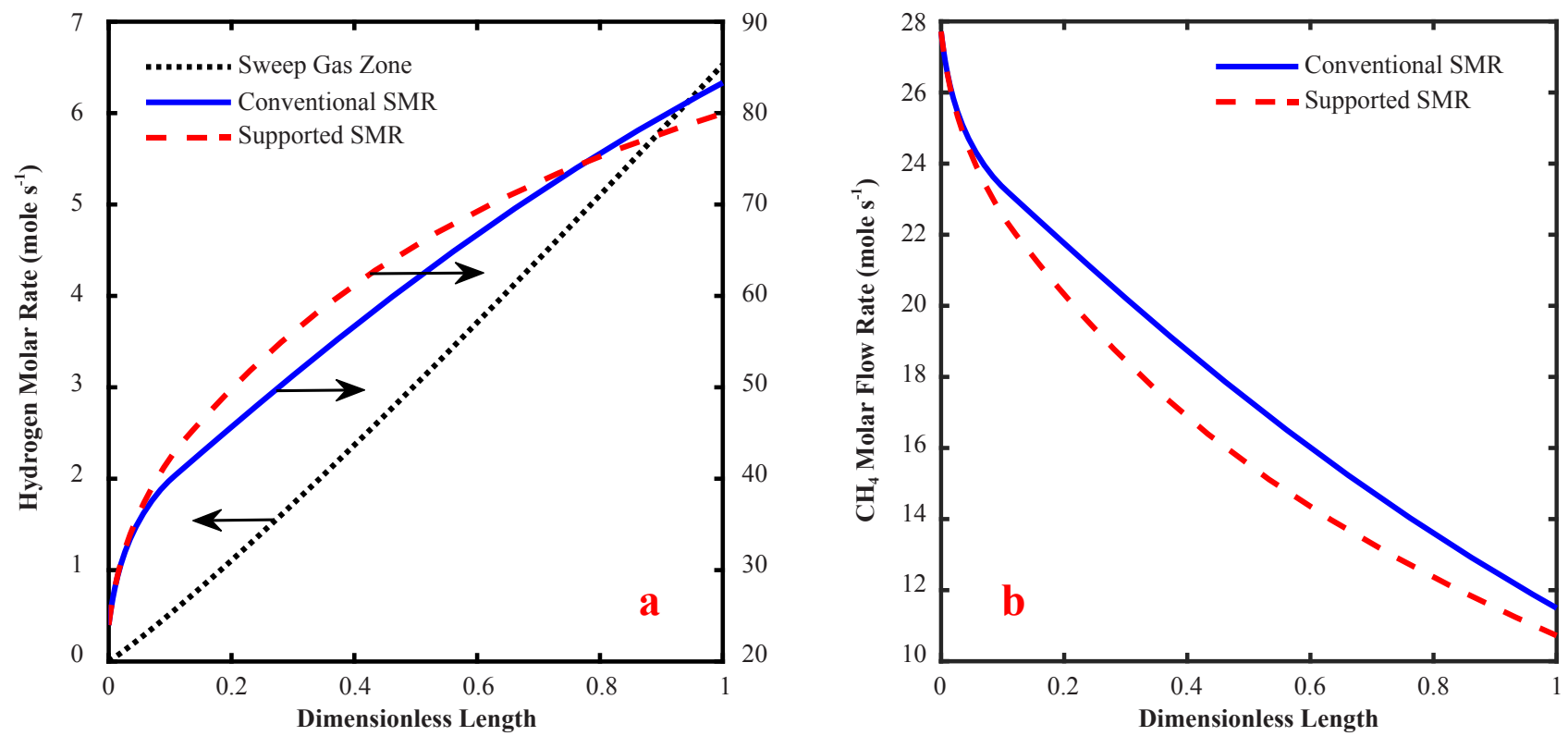

Figure 2. (a) Hydrogen and (b) methane flow rate along the reformer tube

Figure 3 shows the temperature trajectories along the membrane supported and conventional reformers at the same operating condition. Typically, the considered membrane reactor consists of two coaxial tubes that the annulus space between tubes is packed with the catalyst. In the membrane configuration, the membrane module is surrounded by the 
reaction zone and the coil is placed in the firebox. As a base case, the sweep gas temperature is selected to be upper than the feed temperature. In this regard, the heat is transferred from sweep gas to the reaction zone in the first half of the membrane reactor and sweep gas temperature decreases gradually. While the heat transfer direction is reversed in the second part of the membrane supported reformer and sweep gas temperature increases gradually due to low heat consumption in the reaction zone. In general, decreasing methane concentration in the second part of reformer decreases the rate of methane conversion, hydrogen production, and heat consumption.

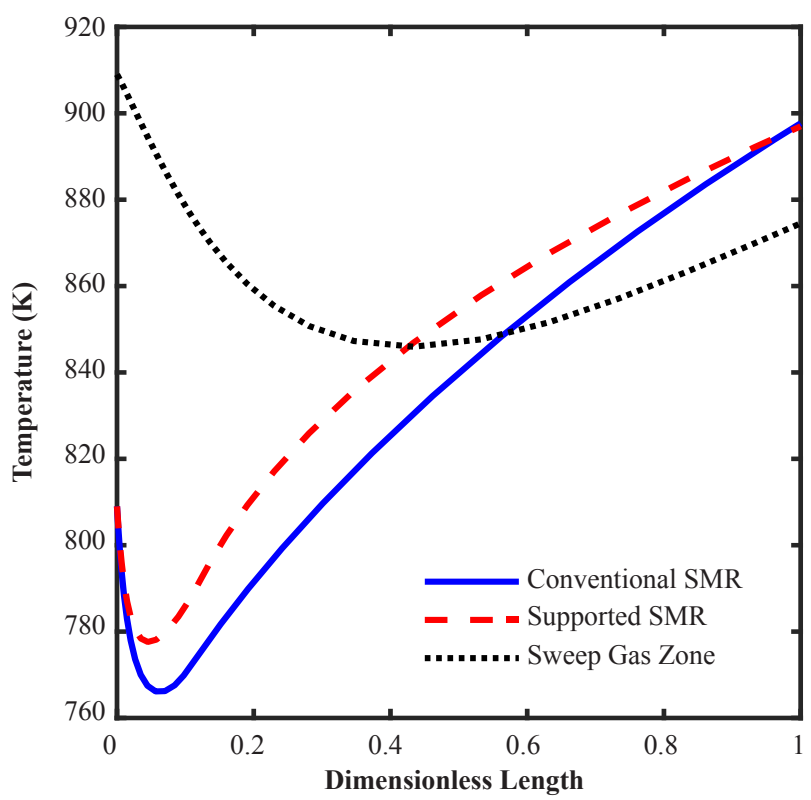

Figure 3. Temperature profile along the coil at the conventional and supported membrane conditions

Figure 4(a) and (b) show the molar flow rate of carbon monoxide and carbon dioxide along the membrane and conventional reformers, respectively. Based on the simulation results, increasing methane conversion in the membrane supported reformer increases carbon dioxide production from 10.68 to $11.53 \mathrm{~mole} \mathrm{~s}^{-1}$.
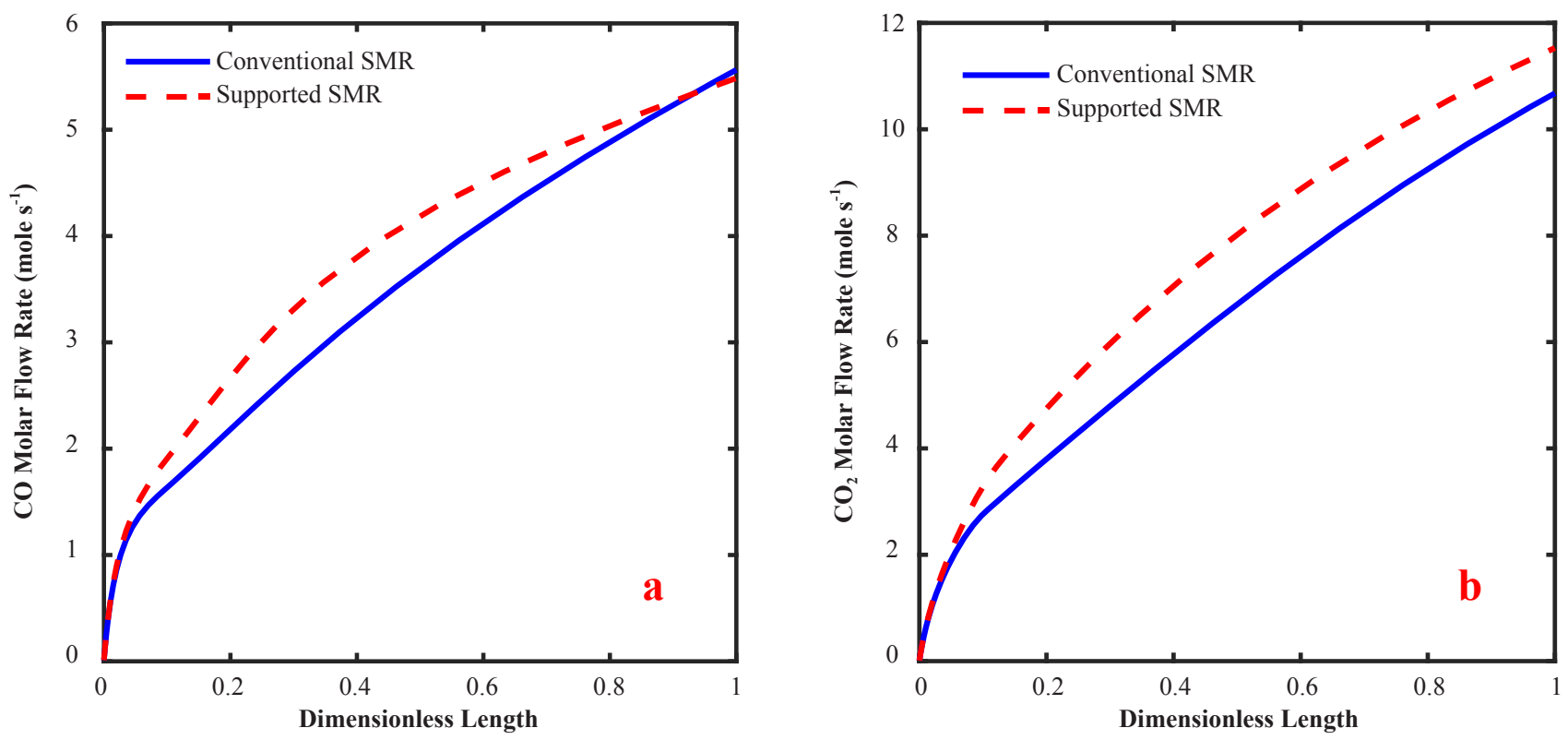

Figure 4. (a) $\mathrm{CO}$ and (b) $\mathrm{CO}_{2}$ molar flow rate along the reformer tube

\subsection{High-temperature shift converter}

In the industrial hydrogen unit, the outlet effluent from reformer is cooled down and feeds to the high temperature 
shift reactor. In the shift converter, the carbon monoxide is converted to hydrogen and carbon dioxide. According to Le Chatelier's principle, hydrogen removal with the membrane module shifts the water gas shift reaction toward the carbon monoxide conversion. Figure 5(a-c) shows the profile of hydrogen flow rate, carbon monoxide flow rate, and operating temperature along the membrane supported and conventional high temperature shift converters. Based on the simulation results, carbon monoxide conversion in the membrane supported and conventional high temperature shift reactors are $81.32 \%$ and $73.60 \%$, respectively. It appears that the heat transfer from sweep gas toward the reaction zone increases reaction temperature and enhances the reaction rate and conversion. Based on the simulation results, the produced hydrogen in the membrane supported and conventional converters are 4.46 and 4.09 mole s$^{-1}$, respectively. Besides, the molar flow rate of hydrogen at the outlet sweep gas from the membrane module is 7.55 mole s$^{-1}$.
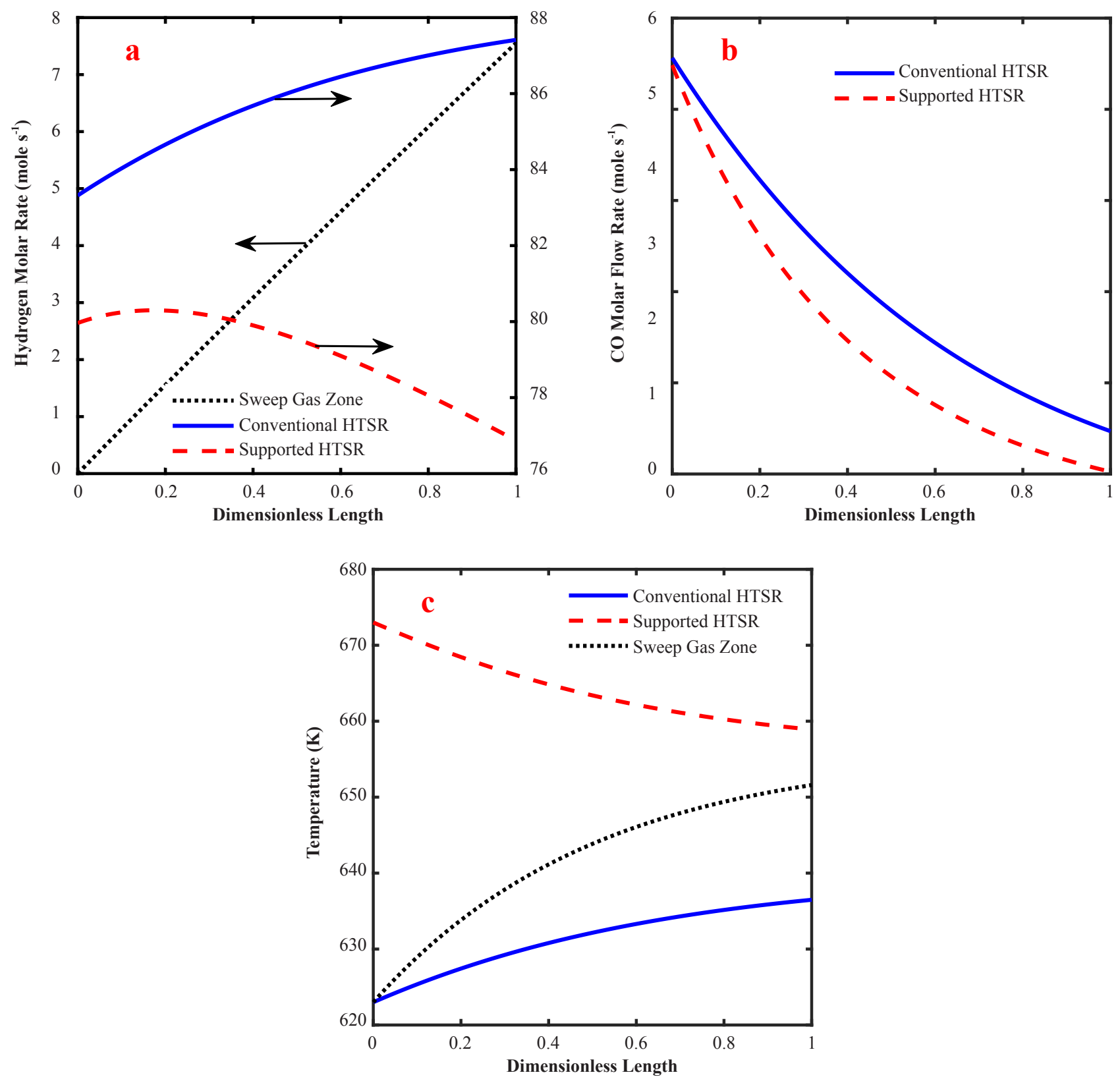

Figure 5. (a) Hydrogen, (b) CO molar flow rate (c) Temperature along the high temperature shift reactor

\subsection{Low-temperature shift converter}

The outlet stream from high temperature converter is cooled down in a heat exchanger and feeds to the low temperature water gas shift reactor. It appears that the low-temperature converter is under equilibrium control and decreasing operating temperature increases equilibrium conversion. As a base case, the temperature of inlet sweep gas to 
the reactor is set to be lower than the feed temperature. Thus, heat transfer from the reaction zone toward the sweep gas could decrease the temperature of reaction zone and shift the reaction toward the hydrogen production. Figure 6(a-c) shows the profiles of hydrogen, carbon monoxide, and temperature along the membrane supported and conventional converters. Based on the simulation results, the molar flow rate of carbon monoxide in the outlet stream from the low shift reactor is 0.03 and $0.06 \mathrm{~mole} \mathrm{~s}^{-1}$ in the membrane supported and conventional configurations, respectively. Typically, hydrogen production is dominant over the hydrogen permeation rate, and hydrogen concentration increases in the first half of membrane converter. Since the shift reaction approaches toward the equilibrium in the second half, the hydrogen permeation rate is dominant over the hydrogen production and hydrogen concentration decreases along the membrane reactor. Based on the simulation results, the hydrogen molar flow rate increases along the sweep gas and approaches to $6.602 \mathrm{~mole} \mathrm{~s}^{-1}$.
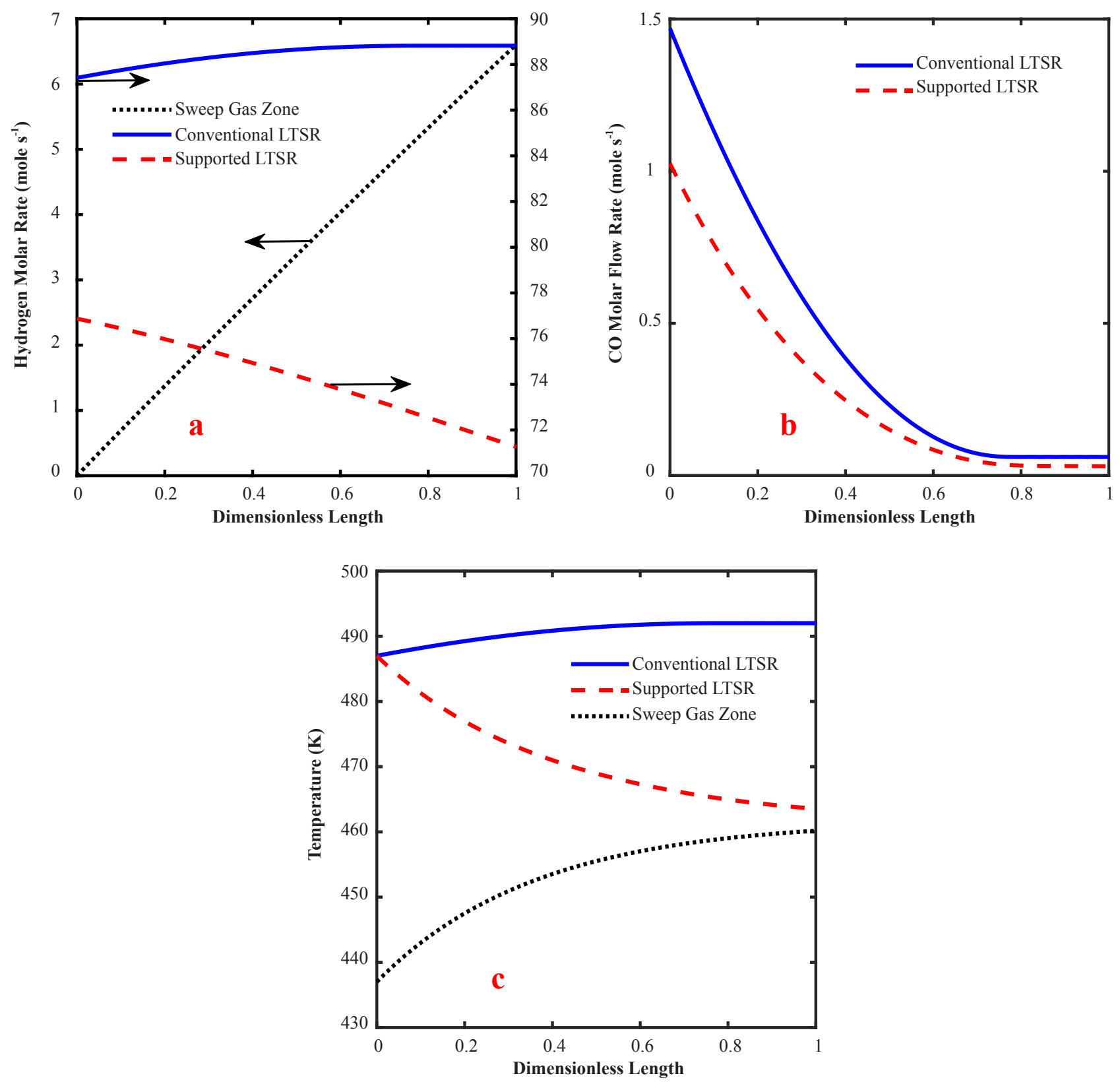

Figure 6. (a) Hydrogen, (b) $\mathrm{CO}$ molar flow rate (c) Temperature along the low temperature shift reactor

\section{5 $\mathrm{CO}_{2}$ absorber column}

In the absorber, carbon dioxide is absorbed by the aqueous solution of monoethanolamine in a sieve tray column, and outlet stream from the top of absorber feeds to the methanator. Based on the simulation results, the molar flow rate of carbon dioxide in the inlet stream to the absorber is 16.18 and $16.98 \mathrm{~mole} \mathrm{~s}^{-1}$ in the conventional and membrane supported 
configurations, respectively. Besides, the amine-circulating rate in the membrane-supported configuration is $144.37 \mathrm{~mole} \mathrm{~s}^{-1}$. Since the inlet stream to the absorption column in the membrane configuration is $\mathrm{CO}_{2}$ rich, increasing the amine-circulating rate is necessary to control $\mathrm{CO}_{2}$ concentration at the acceptable level. Figure 7 shows the molar flow rate of carbon dioxide along the absorption column in the conventional and membrane-supported processes.

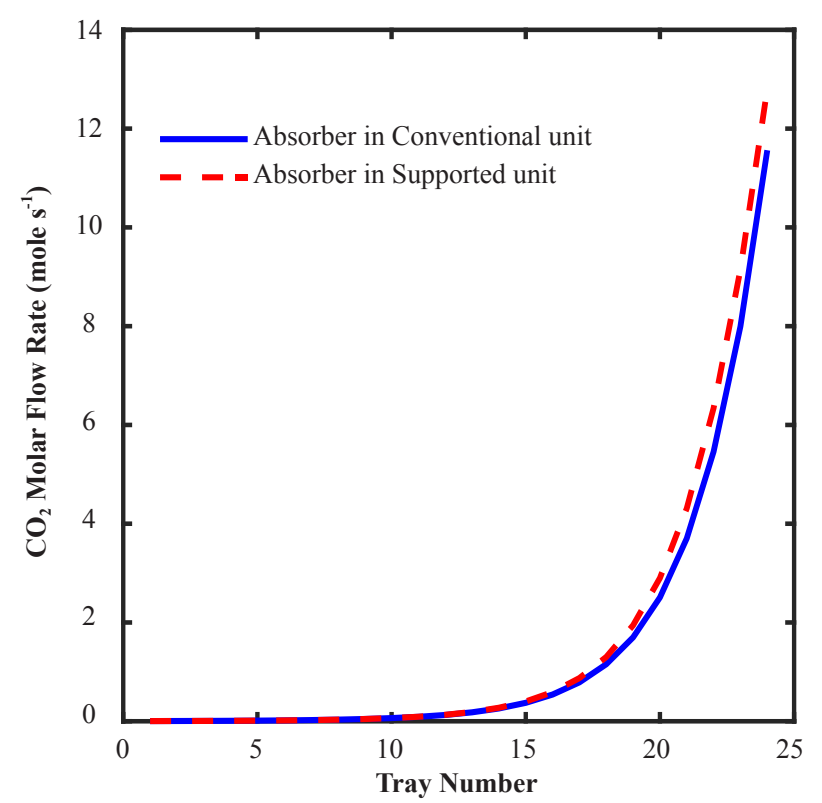

Figure 7. The carbon dioxide molar flow rate along the absorption column

\subsection{Methanation reactor}

In the methanation reactor, decreasing temperature and steam concentration shift the reforming reactions toward the left side and results in the hydrogenation of carbon dioxide and carbon monoxide. Typically, the main idea to support the methanator by hydrogen permselective membrane is the production of the extra-pure hydrogen. Since the inlet stream to the methanator is hydrogen-rich, hydrogen removal has an insignificant effect on the equilibrium conversion. Figure 8(a-c) shows the flow rate of hydrogen, carbon monoxide, and carbon dioxide along the conventional and membrane methanation reactors. Based on the simulation results, the hydrogen molar flow rate increases along the sweep gas and approaches to 5.50 mole $\mathrm{s}^{-1}$. The CO molar flow rate in the outlet stream from the membrane supported reactor is $7.5 \times 10^{-6}$ mole $\mathrm{s}^{-1}$, while it approaches $9.4 \times 10^{-6}$ in the conventional methanator. The $\mathrm{CO}_{2}$ concentration in the outlet stream from both conventional and membrane methanation reactors is negligible. Generally, the lower carbon monoxide concentration in the inlet stream to the membrane-supported methanator decreases the rate of hydrogen consumption in the system and results in higher hydrogen concentration in the outlet stream. 

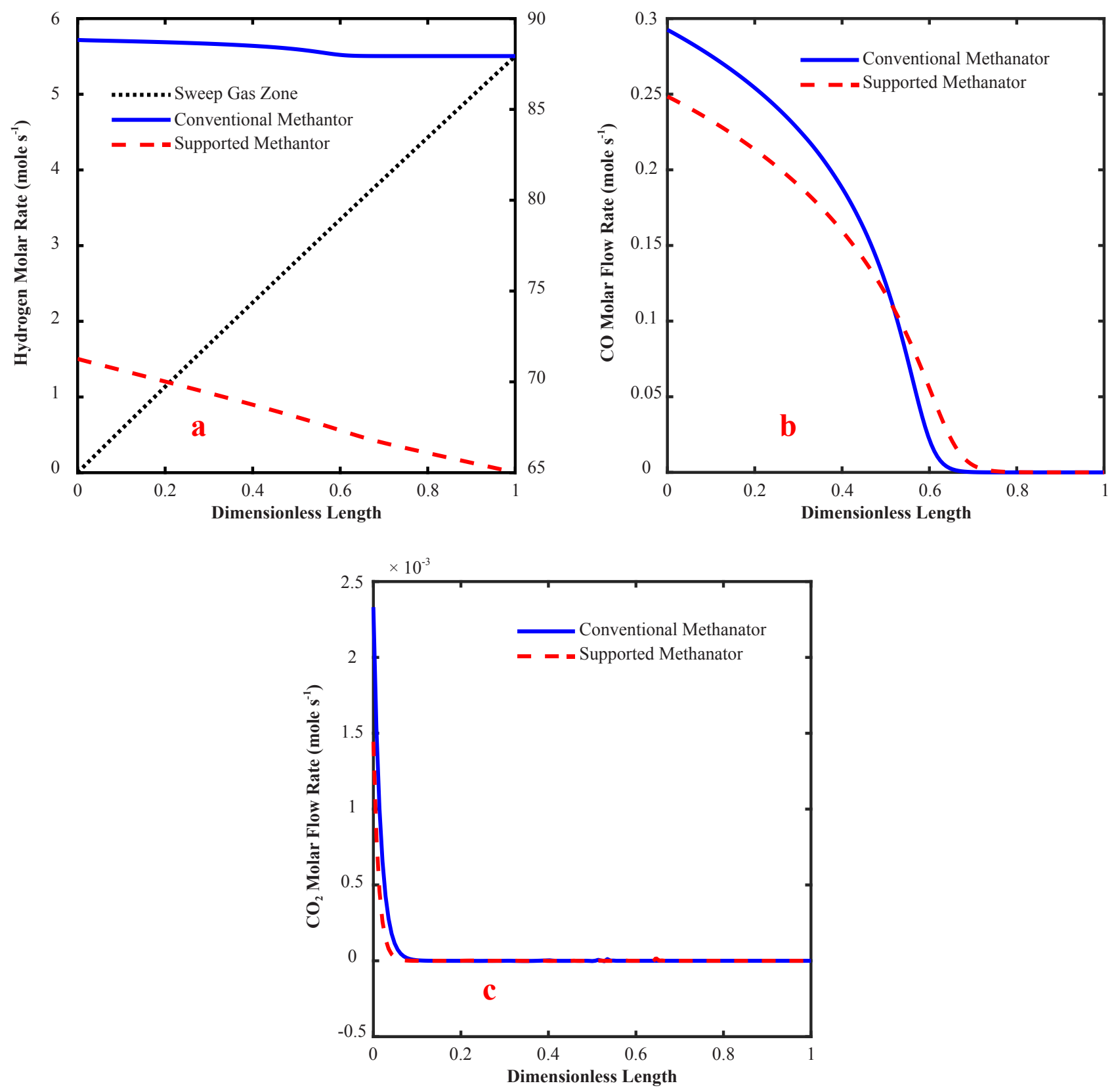

Figure 8. The molar flow rate of (a) hydrogen, (b) carbon monoxide and (c) carbon dioxide along the methanation reactor

\section{Conclusion}

In this paper, a hydrogen production unit in a domestic oil refinery, which comprises steam methane reformer, high and low temperature shift reactors, $\mathrm{CO}_{2}$ absorber and methanator, was modified by hydrogen membrane modules to produce ultra-pure hydrogen. In this regard, palladium-based membrane modules were applied in the reactors. Both membrane supported and conventional processes were heterogeneously modeled based on the mass and energy balance equations at steady state condition. The simulation results showed that supporting the reactors by the membrane module improves the hydrogen production rate and methane conversion by $5.1 \%$ and $5.15 \%$, respectively. The improvement in the hydrogen production rate and methane conversion in membrane supported reformer were $5.34 \%$ and $4.82 \%$, respectively. Besides, supporting shift converters by membrane modules improved reaction rate and equilibrium conversion, and resulted in the higher carbon monoxide conversion to hydrogen. Briefly, the main benefits of proposed system were higher hydrogen production and methane conversion. 


\section{References}

[1] Freal D. M., S. R. Farley, J. M. Emery. Seal assembly for a hydrogen-cooled electric power generator with interface impervious to location of plant piping. United States patent 7432620B2. 2008.

[2] Sørensen, B., G. Spazzafumo. Hydrogen and fuel cells: emerging technologies and applications. 3rd ed. Cambridge: Academic Press; 2018.

[3] Cecere, D., E. Giacomazzi, A. Ingenito. A review on hydrogen industrial aerospace applications. International journal of hydrogen energy. 2014; 39(20): 10731-10747.

[4] Pankove, J. I., N. M. Johnson. Introduction to hydrogen in semiconductors. In: Jacques I. Pankove, Noble M. Johnson. (eds.) Semiconductors and semimetals. Amsterdam, Netherlands: North Holland; 1991. p.1-15.

[5] Sinigaglia, T., F. Lewiski, M. E. S. Martins, J. C. M. Siluk. Production, storage, fuel stations of hydrogen and its utilization in automotive applications-a review. International journal of hydrogen energy. 2017; 42(39): 24597-24611.

[6] Navarro, R. M., M. Pena, J. Fierro. Hydrogen production reactions from carbon feedstocks: fossil fuels and biomass. Chemical reviews. 2007; 107(10): 3952-3991.

[7] Taji, M., M. Farsi, P. Keshavarz. Real time optimization of steam reforming of methane in an industrial hydrogen plant. International Journal of Hydrogen Energy. 2018; 43(29): 13110-13121.

[8] Sarkarzadeh, M., M. Farsi, M. Rahimpour. Modeling and optimization of an industrial hydrogen unit in a crude oil refinery. International Journal of Hydrogen Energy. 2019; 44(21): 10415-10426.

[9] Carrara, A., A. Perdichizzi, G. Barigozzi. Simulation of an hydrogen production steam reforming industrial plant for energetic performance prediction. International journal of hydrogen energy. 2010; 35(8): 3499-3508.

[10] Dincer, I., C. Acar. Review and evaluation of hydrogen production methods for better sustainability. International journal of hydrogen energy. 2015; 40(34): 11094-11111.

[11] Kikuchi, E. Membrane reactor application to hydrogen production. Catalysis Today. 2000; 56(1-3): 97-101.

[12] Leonardo Roses, Fausto Gallucci, Giampaolo Manzolini, Martin van Sint Annaland. Experimental study of steam methane reforming in a Pd-based fluidized bed membrane reactor. Chemical Engineering Journal. 2013; 222: 307320.

[13] Silva, L. C., Murata, V. V., Hori, C. E., Assis A. J. Hydrogen production from methane steam reforming: parametric and gradient based optimization of a Pd-based membrane reactor. Optimization and Engineering. 2010; 11: 441-458.

[14] Farsi, Shahhosseini. A modified membrane SMR reactor to produce large-scale syngas: modeling and multi objective optimization. Chemical Engineering and Processing. 2015; 97: 169-179.

[15] Shigarov, A., V. Meshcheryakov, V. Kirillov. Use of Pd membranes in catalytic reactors for steam methane reforming for pure hydrogen production. Theoretical Foundations of Chemical Engineering. 2011; 45(5): 595.

[16] D. Mendes A., Mendes L., M. Madeira, A. Iulianelli, J. M. Sousa, A. Basile. The water-gas shift reaction: from conventional catalytic systems to Pd-based membrane reactors-a review. Asia-Pacific Journal Of Chemical Engineering. 2010; 5: 11-137.

[17] Boutikos, Nikolakis. A simulation study of the effect of operating and design parameters on the performance of a water gas shift membrane reactor. Journal of Membrane Science. 2010; 350: 378-386.

[18] Ohya, H., J. Fun, H. Kawamura, K. Itoh, H. Ohashi, M. Aihara, S. Tanisho, Y. Negishi. Methanation of carbon dioxide by using membrane reactor integrated with water vapor permselective membrane and its analysis. Journal of Membrane Science. 1997; 131(1-2): 237-247.

[19] Buxbaum, R. E., A. B. Kinney. Hydrogen transport through tubular membranes of palladium-coated tantalum and niobium. Industrial \& Engineering Chemistry Research. 1996; 35(2): 530-537.

[20] Brunetti, A., A. Caravella, G. Barbieri, E. Drioli. Simulation study of water gas shift reaction in a membrane reactor. Journal of Membrane Science. 2007; 306(1-2): 329-340.

[21] Gallucci, F., L. Paturzo, A. Famà, A. Basile. Experimental study of the methane steam reforming reaction in a dense $\mathrm{Pd} / \mathrm{Ag}$ membrane reactor. Industrial \& engineering chemistry research. 2004; 43(4): 928-933.

[22] Elnashaie, Alhabdan. Mathematical Modeling and Computer Simulation of Industrial Water-Gas Shift Converters. Mathl Compur. 1989; 12(8): 1017-1034.

[23] Mohammady Maklavany. Kinetic Modeling of Low Temperature Water-Gas Shift Reaction using gPROMS. American Journal of Oil and Chemical Technologies. 2016; 4(2).

[24] Lv, B., B. Guo, Z. Zhou, G. Jing. Mechanisms of $\mathrm{CO}_{2}$ capture into monoethanolamine solution with different $\mathrm{CO}_{2}$ loading during the absorption / desorption processes. Environmental science \& technology. 2015; 49(17): 1072810735 .

[25] H. Hikita, S. Asai, H. Ishikawa, M. Honda. The Kinetics of Reactions of Carbon Dioxide with Monoethanolamine, Diethanolamine and Triethanolamine by a Rapid Mixing Method. The Chemical Engineering Journal. 1977; 13: 7-12.

[26] Rönsch, S., Köchermann, J., Schneider, J., Matthischke, S. Global Reaction Kinetics of $\mathrm{CO}$ and $\mathrm{CO}_{2}$ Methanation for 
Dynamic Process Modeling. Chem. Eng. Technol. 2016; 39(2): 208-218.

[27] Gilbert Froment, Kenneth B., Bischoff. Chemical reactor analysis and design. Hoboken: Wiley; 1979.

[28] Li, C. -H., B. A. Finlayson. Heat transfer in packed beds-a reevaluation. Chem. Eng. Sci. 1977; 32(9): $1055-1066$.

[29] Nemec, D., J. Levec. Flow through packed bed reactors: 1. Single-phase flow. Chemical Engineering Science. 2005; 60(24): 6947-6957.

[30] Bhandari, R. The synthesis of Pd-Ag composite membranes for $\mathrm{H}_{2}$ separation using electroless plating method. Worcester: Worcester Polytechnic Institute; 2010.

[31] Farsi, M., M. Khademi, A. Jahanmiri, M. Rahimpour. Optimal conditions for hydrogen production from coupling of dimethyl ether and benzene synthesis. International Journal of Hydrogen Energy. 2011; 36(1): 299-310.

[32] Afkhamipour, M., M. Mofarahi. Comparison of rate-based and equilibrium-stage models of a packed column for postcombustion $\mathrm{CO}_{2}$ capture using 2-amino-2-methyl-1-propanol (AMP) solution. International Journal of Greenhouse Gas Control. 2013; 15: 186-199.

[33] Lichtenthaler, R., E. De Azevedo, J. Prausnitz. Molecular Thermodynamics of Fluid Phase Equilibria. New York: Prentice Hall, Inc; 1998. 